\title{
Approachesto Solution Some Problems on the Protection of Erosion Soils in Azerbaijan
}

\author{
ZH Aliev* \\ Institute of Soil Science and Agrochemistry of ANAS, Russia \\ *Corresponding author: ZH Aliev, Institute of Soil Science and Agrochemistry of ANAS, Russia
}

ARTICLE INFO

Received: 蔧 June 25, 2020

Published: 慧 July 01, 2020

Citation: ZH Aliev. Approachesto Solution Some Problems on the Protection of Erosion Soils in Azerbaijan. Biomed J Sci \& Tech Res 28(4)-2020. BJSTR. MS.ID.004678.

Keywords: $\quad$ Inclined $\quad$ Slopes; Erosion;Surface Erosion; Erosion;Environmental Conditions;Stripes

\section{ABSTRACT}

\section{Annotation}

430 million hectares of land was damaged as a result of erosion processes in different countries of the world. Surface, split and irrigation erosion is also widespread throughout the country. $43.29 \%$ of the total area is subject to varying degrees of erosion. In some regions, especially in the Nakhchivan Autonomous Republic, erosion processes cover $70 \%$ of the area. 66.6 of the total area of the southern slope of the Greater Caucasus underwent erosion. In some areas of the country, the percentage of destroyed farms is high. This figure is $51 \%$ in the Lachin-Kelbajar zone, $57.9 \%$ in the Guba-Khaimaz zone and $72.4 \%$ in Sheki-Zagatal. The newly formed fragments break agricultural land into small parts and make them useless. The following erosion intensity scale is presented. 1) clean washing up to $0.5 \mathrm{t} / \mathrm{ha}, 2$ ) poor washing up to 0.5 $\mathrm{t} / \mathrm{ha}, 3$ ) moderate washing 1-5 t / ha, 4) strong washing $-5-10 \mathrm{t} / \mathrm{ha}, 5$ ) very strong wash $-10 \mathrm{t} / \mathrm{ha}$. In different geographical areas of the country, the possible distances between the strips on different slopes were also determined.

Soil preparation should be carried out with a strip of 1-2 m every 3-5 $\mathrm{m}$ in zones with a 10-200 frequency, from moderate to heavy and a width of 1.5-3 m in each of 2-3 $\mathrm{m}$ in highly washed areas of 20-300 m trench to dig. In large areas with more than 15-200 thick and thick soils and where the tractor can work, deforestation should be carried out on terraces. On slopes where heavily washed and often hard rocks are exposed, soil can be set up to create yards and ditches. In different geographical areas of the country, the possible distances between the strips on different slopes were also determined. Soil preparation should be carried out with a strip of 1-2 m every 3-5 m in zones with a 10-200 frequency, from moderate to heavy and a width of 1.5-3 $\mathrm{m}$ in each of 2-3 m in highly washed areas of 20-300 m trench to dig. In large areas with more than 15-200 thick and thick soils and where the tractor can work, deforestation should be carried out on terraces. On slopes where heavily washed and often hard rocks are exposed, soil can be set up to create yards and ditches. In different geographical areas of the country, the possible distances between the strips on different slopes were also determined.

Soil preparation should be carried out with a strip of $1-2 \mathrm{~m}$ every $3-5 \mathrm{~m}$ in zones with a 10-200 frequency, from moderate to heavy and a width of $1.5-3 \mathrm{~m}$ in each of 2-3m in highly washed areas of 20-300 m trench to dig. In large areas with more than 15-200 thick and thick soils and where the tractor can work, deforestation should be carried out on terraces. On slopes where heavily washed and often hard rocks are exposed, soil can be set up to create yards and ditches. In large areas with more than 15-200 thick and thick soils and where the tractor can work, deforestation should be carried out on terraces. On slopes where heavily washed and often hard rocks are exposed, soil can be set up to create yards and ditches. In large areas with more than 15-200 thick and thick soils and where the tractor can work, deforestation should be carried out on terraces. On slopes where heavily washed and often hard rocks are exposed, soil can be set up to create yards and ditches. 


\section{Introduction}

A significant increase in agricultural productivity and sustainability is necessary to meet the population's demand for food and agricultural raw materials(Figure 1). For this purpose, it is important to take comprehensive measures to improve soil fertility, apply intensive agricultural technologies and carry out extensive erosion control measures. The quantity and quality of agricultural products largely depends on the availability of water in the fields. Although there is no irrigation water in our country, and in some cases droughts are observed, some of the precipitation and snow, as well as irrigation water, are lost from the territories. As a result of erosion processes in different countries of the world, 430 million hectares of land were destroyed. Surface, split and irrigation erosion is also widespread throughout the country. $43.29 \%$ of the total area is subject to varying degrees of erosion. In some regions, especially in the Nakhchivan Autonomous Republic, erosion processes cover $70 \%$ of the area. 66.6 of the total area of the southern slope of the Greater Caucasus underwent erosion. In some areas of the country, the percentage of destroyed farms is high. For example, this indicator is $51 \%$ in the Lachin-Kelbajar zone, 57.9\% in GubaKhaimaz and $72.4 \%$ in Sheki-Zagatala. Newly formed splinters smash agricultural these lands into small parts and make them useless. Gully material covers valuable plantations and pollutes wetlands. Reclamation measures against erosion provide effective regulation of surface runoff, improving the water regime of the soil, maintaining the level of fertility. This review discusses the laws of soil washing, the formation of surface runoff, some theoretical and practical problems in the fight against erosion. There are disputes in the issues under consideration. Therefore, these data are summarized for an objective assessment. Irrigation erosion is not resolved. The article uses the results of studies conducted by TAI Laboratory "Soil Erosion" (former Institute of Erosion and Irrigation of the Academy of Sciences)[1].

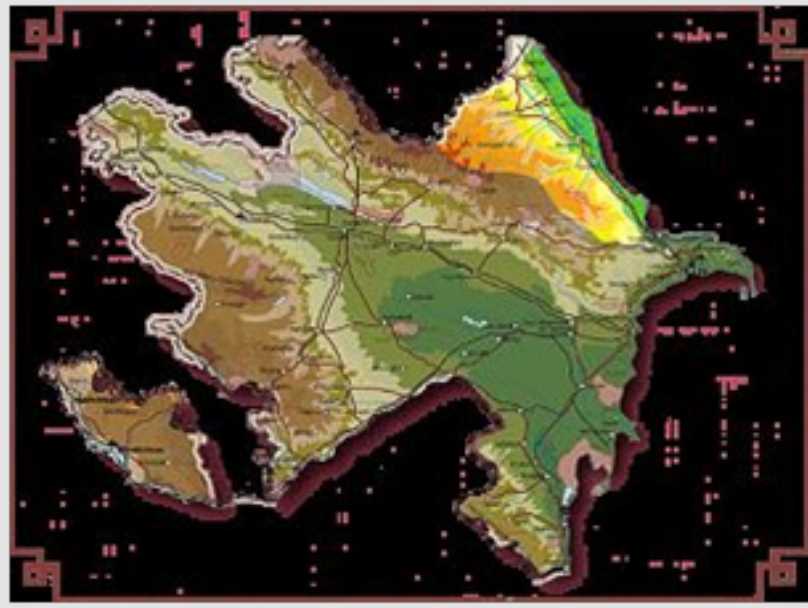

Figure 1.

\section{The Scientific Basis for the Protection of Soils from Water Erosion}

\section{Damage caused by Environmental Erosion and Agriculture}

Under the concept of water erosion, soil degradation is understood as the process of soil erosion and depletion through streams, as well as landscape degradation processes. Water erosion is the main cause of degradation of soils and natural complexes. Water erosion in nature occurs in two ways: surface erosion and (linear argan) erosion. Surface erosion does not occur immediately, especially at the initial stage. In fact, an area of 100 acres per $100 \mathrm{~m}$, an average width of $5 \mathrm{~m}$ and a depth of $2 \mathrm{~m}$ is formed on an area of one hundred hectares, and this does not go unnoticed. Nevertheless, when washing $1 \mathrm{~cm}$ of soil from this place, this is barely noticeable, although as a result of the development of this ravine, 10,000 m3 of valuable soil and soil are lost as a result of washing a 1-centimeter layer of $600-800 \mathrm{~m} 3$ and 100 ha. Therefore, surface erosion is much more dangerous. Washed areas cost \$1 million annually. On unused coastal territories they increase by 100-150 thousand ha, and on moving sands they increase by 40-50 million ha. As a result of erosion, the average annual incidence of soil is 30-40 tons per hectare, and sometimes more[2].

2-3 billion tons of sown and sown areas per year.Soil, including 100 million tons of humus and 43 million tons of soil. Nitrogen, aosaor, potassium are washed. This is 1.5 times more nutrients entering the soil in the form of mineral fertilizers. $22.3 \%$ of the country's forests are under erosion of the All-Union (4.5 ha) per capita ( $0.2 \mathrm{ha}$ ) and are subject to erosion. Significant changes in the microclimate characteristics of such areas occur, forests do not play a role in soil and water management, and after heavy rains there is a huge destructive flood. As a result of erosion, $118400 \mathrm{~m} 3$ of soil enters the Kishchay basin every year from the slopes. Suffice it to say that, according to archival documents, as a result of severe landslides in the Kish basin on July 15, 1988, \$ 27 million was invested in enterprises and enterprises of the Sheki district. b. damaged. In mountain meadows, which are used as summer pastures of the republic, there is a rapid development of erosion processes due to overgrazing and overgrazing.As a result, vegetation deteriorates, its composition deteriorates, soil structure and structure are disturbed and strengthened, and the surface is absorbed by surface flows without absorbing soil. $80-91.2 \%$ of the summer pastures of Guba, Gadabay, Dashkesan, Khanlar and Sheki are prone to erosion and reduce productivity by 1.5-3.0 times. And changes in the vegetation cover (deterioration of fodder resources, etc.) will undoubtedly affect the wildlife, especially its migration, which is extremely sensitive to the environment. The above proves that the intensive development of erosion affects agricultural production and the environment, and the development and 
implementation of effective measures to combat erosion are one of the most important areas of the day[3].

\section{Justification of Erosion Control Measures}

In developing measures to combat erosion, the intensity of surface runoff and soil washing, erosion of eroded soils, etc. are taken into account. The goal here is to create conditions to prevent surface formation on the upper slopes of the slope. If this cannot be prevented by existing means, it is intended to store particles in the required area of the soil, to prevent excessive washing of small particles of soil. In recent years, various modeling methods have been used for this purpose. Examples of this are simple mathematical models (map of washed soils, etc.). Predictive problems are used to justify soil conservation measures. The universal equation proposed by American scientists can be widely used to predict soil loss. Washed lands are allotted to justify the system of countermeasures, to maintain and increase the fertility of the land. In order to characterize the general soil leaching in the cultivation slope zone, it is recommended to calculate the recommended average soil leaching index (Pop) in this area using the following formula:

$\mathrm{Pop}=\left(\left(\mathrm{P}_{-}\left(1 \mathrm{~S}_{-} 1+\mathrm{P} 2 \mathrm{~S} 2+\mathrm{P} 3 \mathrm{~S} 3+\cdots . .+\mathrm{PnSn}\right)\right)\right) /$ one hundred

Here Pop is the average soil leaching rate, P1, P2, P3, etc. The number of washing elements of the soil contour is S1, S2, S3, and so on. elements of the soil contour area. If, as a diagnostic indicator, when washing the soil, the humus content in the 0-50 cm layer decreases, then P1, P2, P3 should reflect the amount of humus in the $0-50 \mathrm{~cm}$ layer.The universal equation for evaluating erosion processes is not enough. Australian National University uses cesium adsorbed by soil particles to map eroded soils. In the former SSPI, the permissible threshold for washing black soils is from 3 to 5 tons per hectare. However, it is believed that the maximum permissible amount of soil leaching for Azerbaijani conditions should not exceed 0.2-0.5 tons. So much significant loss of the land itself is not offset by an increase in the fertility of such lands. The following erosion intensity scale is presented. 1) easy washing up to $0.5 \mathrm{t} / \mathrm{ha}$, 2) poor washing up to $0.5 \mathrm{t} / \mathrm{ha}, 3$ ) moderate washing 1-5 $\mathrm{t} / \mathrm{ha}, 4$ ) strong washing -5-10 t / ha, 5) more severe washing -10 t / ha[4].

\section{Integrated Erosion Control Measures on the Slopes}

Integrated erosion control measures include economic, organizational, agricultural, meadow, forest and irrigation and drainage measures. The implementation of these measures should at the same time prevent the negative impact of all types of natural and economic activities and provide an opportunity to increase the productivity of their lands[5].

\section{Organization of the Territory as an Important Part of Erosion Control}

The erosion control of the territory, the composition and proportions of the agricultural sector, measures to increase its productivity, types and types of crop rotation, the number of agricultural land, alternative plantings, hydraulic structures, forest belts, borders and settlements, the volume of agricultural work. identifies problems. For this, a general scheme of anti-erosion management of individual farms, administrative regions, provinces and the country is being developed. Land use projects intended for individual farms are of greater practical importance. Such projects in our country are designed for a maximum of 1:10000 and partly for 1: 25000. When drafting an erosion control zone project for a given area. First of all, natural conditions are analyzed. To this end, the Center for Agroecological Sciences conducted relevant studies in almost all mountain and foothill regions of the country, as well as maps of soil erosion maps and cartograms, erosion factors, and antierosion measures. Intermediate cultivation should be preferred on slopes with 5-60 slopes prevailing on untreated and poorly washed soils, and crops on 6-120 slopes. At the end, inter-row vegetation should be $20-25 \%$, perennial grasses $30-40 \%$. Soil protection should be widely used on slopes with a moderate or moderately strong slope of 12-150 (on moderately washed soils), and in areas with strong washing should not be used as natural cuttings[6].

The low efficiency of the erosion control organization of the territory is mainly due to the poor location of road and forest lanes within the boundaries of arable land. In most cases, the linear elements shown are arranged so that they move up and down the slope. This leads to the accumulation of surface currents along slopes, roads and other structures and the rapid development of erosion processes. The longest sides of the cultivated areas should be in the direction of the slope to effectively prevent surface currents.

Project development begins with the identification of more feasible areas of specialization of the economy, taking into account protection from soil erosion. On the basis of a detailed study of natural conditions, alternative plantings are developed, the technology of crop erosion, the development of a fertilizer system, slope and other useless areas, the development of erosion forest plantations and hydraulic structures, roads, etc.A number of farms in the country have begun to use land improvement systems to prevent erosion and increase productivity by regulating surface flows. This system assumes that all work on plowing and cultivation is carried out in accordance with relief horizons, the creation of water-holding and retaining posts and dams in erosion-prone areas and on the outskirts of farms, laying of wooden strips along the edges, and special agricultural technology. Measures[7].

\section{Phyto-Reclamation Measures Involving Hydraulic Devices}

Anti-erosion agromelioration is a biological engineering system. Protective forest belts and hydraulic engineering anti-erosion agents are the main elements of this system. Forest plantations cause both surface and internal flows to leak into the soil and retain most of the nutrients. The amount of nutrients decreases by 4-5 times in the surface course of forest strips in sown areas. Amount of nitrates 
in water released from livestock to The complexes at this time are between 23 and $4.2 \mathrm{mg}$ / kg.l, nitrites are reduced from 1.42 to 0.12 $\mathrm{mg} / \mathrm{l}$, and phosphorus is 1.5 times. All this prevents pollution of surface and inland waters and water sources. Protective forest belts are often used in combination with simple hydraulic structures to increase erosion efficiency. In the trench forest strip $0.6 \mathrm{~m}$ deep, 1.2 $\mathrm{m}$ deep and $0.1 \mathrm{~m}$ deep between the bottom line, almost all surface runoff from the basin is preserved. In the North Caucasus, the flows of the fault surface decreased by 6-8 times. The last century Since the 1970s, on the southern slopes of the Greater Caucasus, erosion was carried out on the field with various soil preparations (tar, trenches, strips) and their effect on soil leaching[8].

At that time, 18,785 tons of land was washed out from each controlled hectare (not forest area), a total of 955 and $2210 \mathrm{~g}$ of soil was washed out from the area prepared by the resin and strip method. One of the most important principles for creating forest strips is their correct location or slope. Distances between the strips along different slopes are also determined for different geographical zones of Azerbaijan. Soil preparation should be carried out with a strip of 1-2 m every 3-5 m in zones with a 10-200 frequency, from moderate to heavy and a width of 1.5-3 $\mathrm{m}$ in each of 2-3 $\mathrm{m}$ in highly washed areas of 20-300 m trench to dig. In large areas with more than 15-200 thick and thick soils and where the tractor can work, deforestation should be carried out on terraces. On slopes where heavily washed and often hard rock is exposed, soil can be prepared to create tar and trenches. Forest reclamation measures are used to strengthen gorges and caves. For this purpose, trees and shrubs are planted along the edges, slopes and bottoms, with a strong root system and bearing capacity, which does not require moisture and soil fertility[9].

In this case, depending on the slope and soil conditions, it may be more profitable to prepare the soil on slopes and slopes, with terraces, slopes, trenches and slabs, as well as slopes and bare sections. In almost all horticultural areas, the use of simple hydraulic drilling rigs, trenches, fragments and cracks is more efficient. They function more efficiently when filled with stems, manure and organic leaves. In gardens located on slopes (12-140), spraying intervals play a positive role. Most summer and winter pastures in our country need serious surface improvement. Improving mowing and haircuts should be carried out comprehensively At the same time, simple hydraulic structures (water intake and holding dams, poles, etc.) are not only aggravated by agricultural measures (plowing strips, buffer strips, splitting, etc.), but the main role is to prevent and flush the soil . $\mathrm{m}$ It is necessary to ensure land reclamation (planting of perennial grasses), create cultivated pastures and weeds[10].

\section{Reclamation}

Erosion is rapidly developing in the mountainous and foothill areas of the republic, which in recent years has been one of the most dangerous and destructive types of soil erosion. Over the past ten years, the area of unused fleas in our country has grown by more than 5 million tons. 6.6 million ha of sown area. Their length reached 1 million $\mathrm{km}$, and their total number reached 13 million. As a result of the development of ravines, the area of farmland increases annually by 100-150 thousand ha. Recently, new methods of reclamation of crushed areas in the agricultural sector of the country and abroad are widely used. This struggle includes partial or complete replenishment of the slopes with the preservation of the fertility of the upper layers of the soil or their slopes, filled with a tendency to the development of agricultural plants, which allows machines and mechanisms to function. Fundamental land reclamation should be based on a pre-recorded project. The filling slope is divided into separate sections of 20-25 meters, depending on the total length. The volume of earthwork is calculated based on the size of the ridge (width, length and depth).

Then a decision is made whether the orientation of the project will be chosen - how appropriate is the slope of the slope that needs to be completed. Subsequently, at a depth of 2-5 m from the top of the ravine, dams with a depth of 30-40 $\mathrm{cm}$ or waterlogging are created to prevent surface runoff from entering the reclamation zone. Then the filling of the fleet begins. A bulldozer, a loan, can be used as landing machines, such as a sniper and an excavator. First, the bulldozer removes three fertile layers of humus from the first working area, and this section is filled to the required depth. Then the bulldozer moves to the second zone of the first zone, moving the humus layer to the surface. The second area is filled with copper. Work in other areas is ongoing in the same sequence. Perennial grasses are planted in this area to protect the smoothed area from further erosion, and these areas will be used for 2-3 years. Soils are given high doses of organic and mineral fertilizers. It is recommended to use for slopes with relatively soft clays with a water depth of not more than 5-10 hectares, located on slopes 10-150, 300-450 $\mathrm{m}$ long and an average depth of 5-7 $\mathrm{m}$. The implementation of these measures in our country every year will help to obtain a significant amount of additional land due to useless soils and protect the most valuable natural resources.

\section{Interactions of Elements of Integrated Control Mea- sures}

The fight against erosion is a complex, labor-intensive process that requires the implementation of comprehensive measures: economic, organizational, agricultural, phyto-reclamation and hydraulic. In connection with the protective conditions of the protective plantations and hydraulic structures, it must be placed in accordance with the principles of land reclamation. When the district is organized on the basis of the reclamation profile and comprehensive measures are implemented, agro-lifts approach their natural stability to almost all precipitation. The interaction of elements of soil measures is quite high. For example, a wooded strip with a gross terrace, reinforced by moats in the form of an interconnected system, completely absorbs atmospheric deposits 
for 5 years. Soil protection systems are also preferred in many countries around the world. However, the application of scientific research in our country does not meet the requirements of soil protection.Sowing soil is poorly used, planting is not carried out on a large scale, and some parts of the planted land cannot fulfill their role due to poor maintenance. Simple hydraulic devices are used on such a small scale. One of the main reasons for this is that the erosion process is accurate enough to assess the real damage to the environment, its pollution and the lack of a unified methodology. For a successful erosion control, it is important to determine the optimal indicators of cultivated areas, meadows, grasses and forests depending on local soil and climatic conditions. To ensure compliance with established standards, environmental and land protection services should be established and adequate staff should be provided. Interest in the protection and conservation of land should also be increased. Soil protection and fertility should be a key criterion for assessing the performance of farm managers and specialists.

\section{Conclusion And Offers}

In recent decades, the intensification of erosion processes is explained by a decrease in the content of humus in the soil, a deterioration in the water-physical properties of soils, and insufficient antimicrobial activity in humans. Water erosion has acquired such proportions that if this continues, $1 / 3$ of the agricultural land in our country may become worthless after 20 years. To justify erosion measures, the processes of erosion were studied and possible land losses were determined. Various modeling methods, empirical equations, new methods of mapping and classification of eroded soils have been proposed. All this allows us to design anti-erosion complexes based on calculations. A successful solution to the problem of water erosion is possible only when using a set of measures to protect the soil, which are interconnected and complement economic, organizational, agricultural, forest, meadow and irrigation and drainage measures. To solve the problem of protecting the soil from erosion, the following are important:

ISSN: $2574-1241$

DOI: 10.26717/BJSTR.2020.28.004678

ZH Aliev. Biomed J Sci \& Tech Res

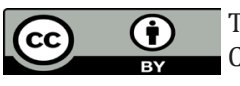

This work is licensed under Creative Commons Attribution 4.0 License

Submission Link: https://biomedres.us/submit-manuscript.php
1. standards should be adopted to determine the relative areas of planting, meadows, grasses, water and forests in accordance with local soil, climatic and economic characteristics.

2. An environmental service should be created to monitor compliance with established standards.

3. specific norms of the optimal ratio of economic areas (as well as forests) as the basis for sustainable agriculture for each zone should be determined by the interaction of the elements of the complex, should be determined;

4. The balance of soil fertility for 10-15 years should be determined. This allows you to control the use of sown areas, take into account the environmental consequences of economic activity and significantly increases the responsibility for the conservation and protection of land resources.

\section{References}

1. Alekperov KA (1961) Soil erosion in Azerbaijan and measures to combat it. Baku Science.

2. BH Aliev, AA Irahimov, ZH Aliyev (2001) The current state of the erosion process in Azerbaijan and the system of measures to combat it (scientific and methodological guidelines). Baku 98.

3. ZH Aliev (2020) Scientific Validity of Approaches to Solving a Number of Agricultural Problems in Azerbaijan. International Engineering Journal (Iej) 1(1): 7-13.

4. Buyakin NI, Mukhamedzhanov VI (1985) Postal addresses for post offices. Emerald p. 41-43.

5. Dubinsky SP, Buryanov VI (1985) Farmhouse agribusiness. Kharkov pp. 216.

6. Zaslavsky MN, Larinov GA, Litvin LF (1984) Mechanisms and patterns of the erosion process. Sat Erosion M Misl p. 31-48.

7. Zarudny Yu K (1985) Lesbian pumps with valleys. To attempt (2): 42-44.

8. Zaslavsky MN (1983) Erosion M High School pp. 320.

9. Rozhkov AG (1975) Bored with the USSR and the Russian Federation M p. 37.

10. Mitchell JK, Bubzenzer GD (1984) Calculation of mailboxes. Saturday M Kolos p. 34-96.

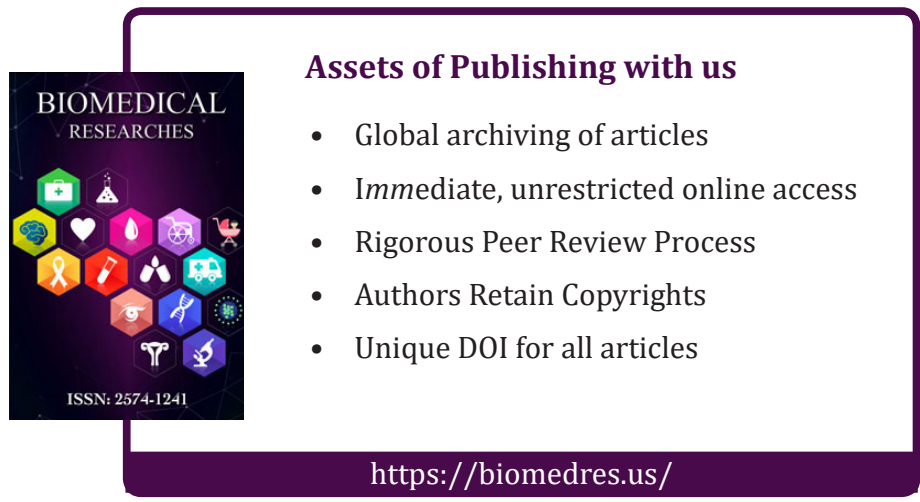

